\title{
Thiophene-Based Oligomers Interacting with Silver Surfaces and the Role of a Condensed Benzene Ring
}

A. Guarnaccio, ${ }^{* \dagger}$ M. D’Auria, ${ }^{\ddagger}$ R. Racioppi,${ }^{\ddagger}$ G. Mattioli, ${ }^{\S}$ A. Amore Bonapasta, ${ }^{\S}$ A. De Bonis, ${ }^{\ddagger}$ R. Teghil, ${ }^{\ddagger}$ K. C. Prince, ${ }^{\|}$R. G. Acres ${ }^{\|, \perp}$ and A. Santagata ${ }^{\dagger}$

${ }^{\dagger}$ CNR-ISM UOS Tito Scalo - C/da S. Loja, 85050 Tito Scalo (PZ), ITALY

F Science Department, Università della Basilicata, Viale dell'Ateneo Lucano 10, 85100 Potenza, ITALY

${ }^{\S}$ CNR-ISM UOS Montelibretti - via Salaria Km 29,300 - 10100015 - Monterotondo Stazione (RM), ITALY

"Elettra Sincrotrone Trieste, Basovizza Area Science Park, 34149 Trieste, ITALY

${ }^{\perp}$ Present Address: Australian Synchrotron, 800 Blackburn Road, Clayton, 3168, Victoria, AUSTRALIA

*corresponding author: ambra.guarnaccio@pz.ism.cnr.it

\section{Supporting Information}

\section{Table of Contents}

Luminescence of the Raman spectra related to bulk molecules.....

XPS $\operatorname{Ag}(3 d)$ spectra of 3T and DTBT adsorbed onto $\operatorname{Ag}(110)$ surface.

Theoretical Carbon K-edge NEXAFS spectrum of isolated 3T and DTBT molecules.

Experimental Carbon K-edge NEXAFS spectra of annealed DTBT after its deposition onto $\operatorname{Ag}(110)$ surface...... S-6

Configurations of 3T and DTBT adsorbed on the Ag surface investigated by ab initio calculations....

S-7 
Luminescence of the Raman spectra related to bulk molecules

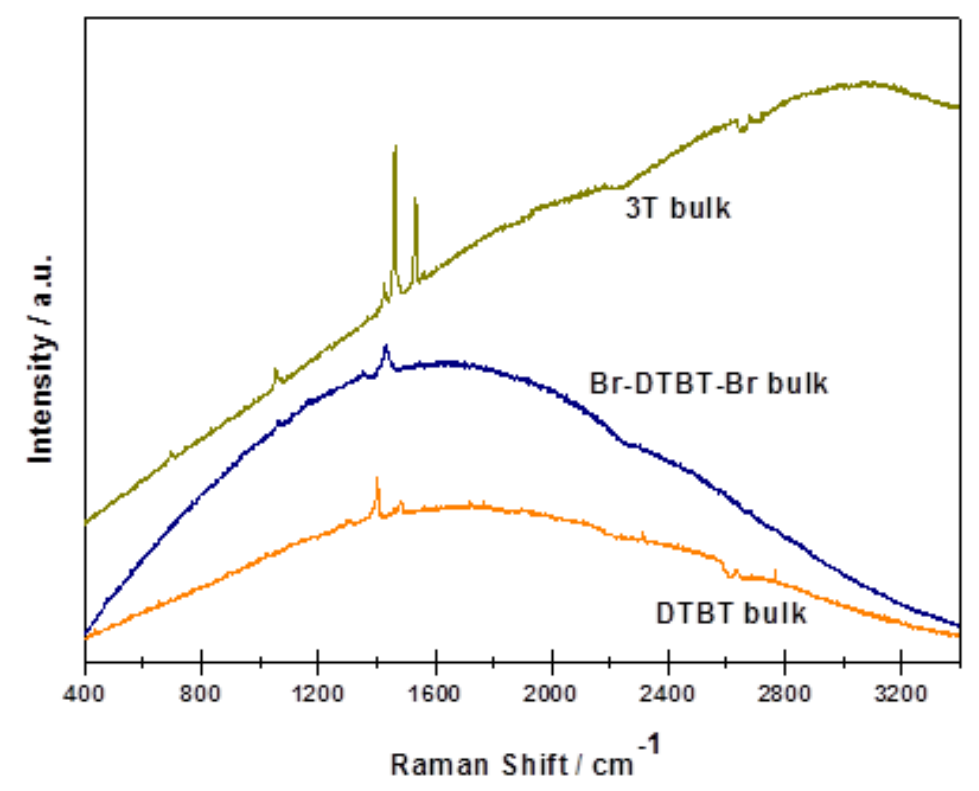

Figure S1. RAMAN background uncorrected spectra related to bulk 3T, DTBT and Br-DTBT-Br molecules. 
XPS Ag(3d) spectra of 3T and DTBT adsorbed onto Ag(110) surface
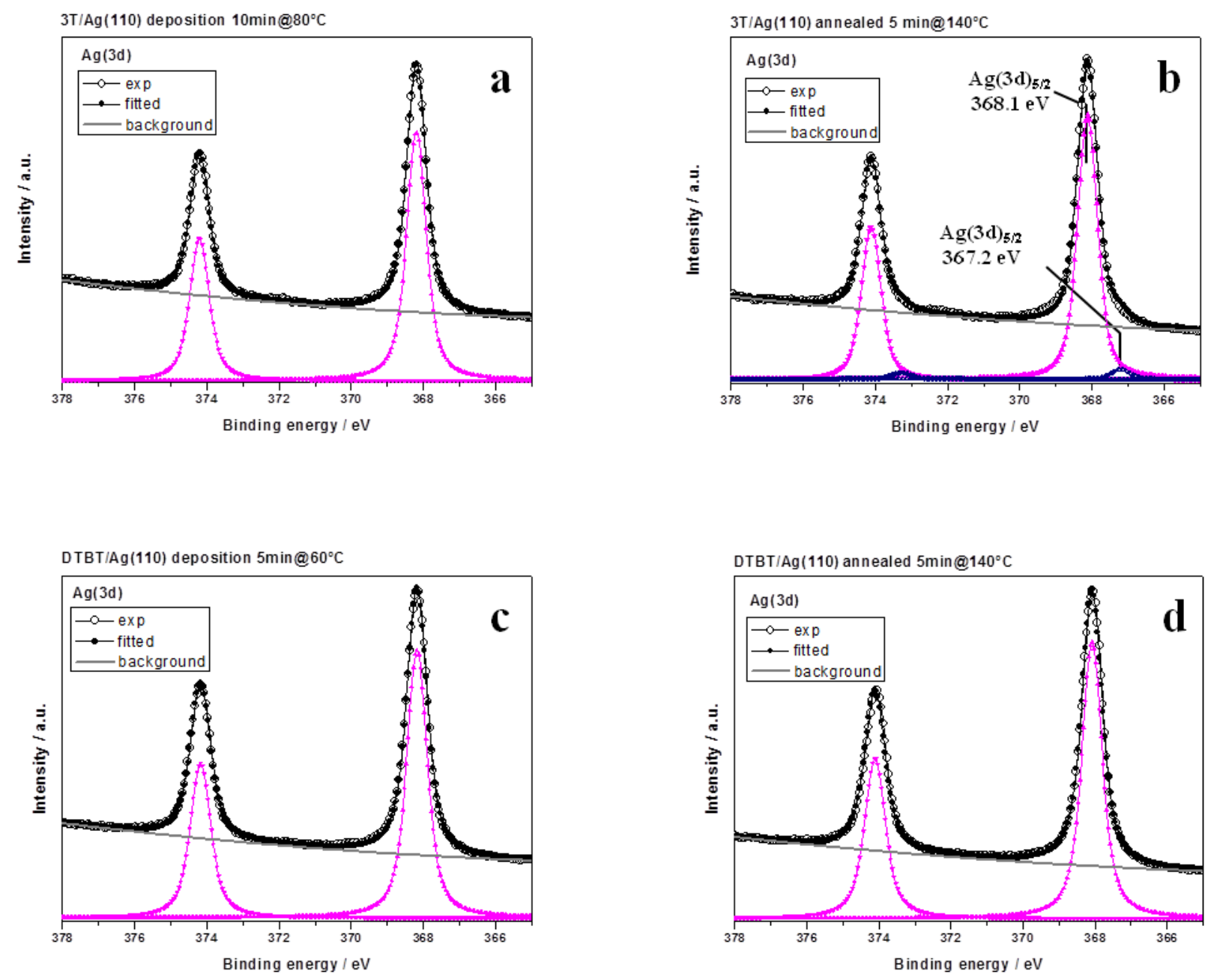

Figure S2. XPS Ag(3d) core level $(h v=430 \mathrm{eV})$ spectra of $\mathbf{3 T}(a, b)$ and DTBT $(c, d)$ deposited onto $\mathrm{Ag}(110)$ in the conditions reported in each spectrum. The open circles represent raw experimental data and dotted lines are the best fitted Voigt curves. 
Table S-I. High-resolution synchrotron XPS Ag(3d) core level $A g(3 d)_{3 / 2}$ and $A g(3 d)_{5 / 2}$ components related to $3 T$ and DTBT molecules deposited onto Ag(110) surface and related assignments.

\begin{tabular}{|c|c|c|c|c|}
\hline & \multicolumn{2}{|c|}{ Ag-Ag } & \multicolumn{2}{|c|}{ Ag-C } \\
\hline & $\operatorname{Ag}(3 d)_{3 / 2}$ & $\operatorname{Ag}(\mathbf{3 d})_{5 / 2}$ & $\operatorname{Ag}(3 d)_{3 / 2}$ & $\operatorname{Ag}(3 d)_{5 / 2}$ \\
\hline $\begin{array}{c}3 \mathrm{~T} / \mathrm{Ag}(110) \\
\operatorname{dep} 10 \min @ 80^{\circ} \mathrm{C}\end{array}$ & $374.2 \mathrm{eV}$ & $368.2 \mathrm{eV}$ & - & - \\
\hline $\begin{array}{c}\text { 3T/Ag(110) } \\
\text { dep + annealing } \\
5 \text { min } @ 140^{\circ} \mathrm{C}\end{array}$ & $374.1 \mathrm{eV}$ & $368.1 \mathrm{eV}$ & $373.3 \mathrm{eV}$ & $367.2 \mathrm{eV}$ \\
\hline $\begin{array}{c}\text { DTBT/Ag(110) } \\
\text { dep } 5 \text { min@ } @ 0^{\circ} \mathrm{C}\end{array}$ & $374.1 \mathrm{eV}$ & $368.1 \mathrm{eV}$ & - & - \\
\hline $\begin{array}{c}\text { DTBT/Ag(110) } \\
\text { dep + annealing } \\
5 \text { min } @ 140^{\circ} \mathrm{C}\end{array}$ & $374.1 \mathrm{eV}$ & $368.1 \mathrm{eV}$ & - & - \\
\hline
\end{tabular}

As shown (Figure S2 and related data summarized in Table S-I) by XPS $\operatorname{Ag}(3 d)$ core level spectra of $3 \mathrm{~T}$ molecule interacting with the $\operatorname{Ag}(110)$ surface, after a high thermal treatments (annealing 5 min@ $140^{\circ} \mathrm{C}$ ) a clear evidence of an Ag-C bond appears. It can be observed that the peak of Ag-C occurs at $367.2 \mathrm{eV}$, which corresponds to $\mathrm{Ag} 3 \mathrm{~d}_{5 / 2}$ binding energy. In comparison with $\mathrm{Ag}-\mathrm{Ag}$ $(368.1 \mathrm{eV})$ the peak was shifted to lower binding energies indicating a change of the chemical environment around $\mathrm{Ag}$ which is compatible with a $\mathrm{Ag}-\mathrm{C}$ bond occurrence. On the contrary, for DTBT system, even following temperature increasing, such evidences have not been obtained since only one silver component (Ag-Ag) has been fitted. ${ }^{1,2}$ 


\section{Theoretical Carbon K-edge NEXAFS spectrum of isolated 3T and DTBT molecules}
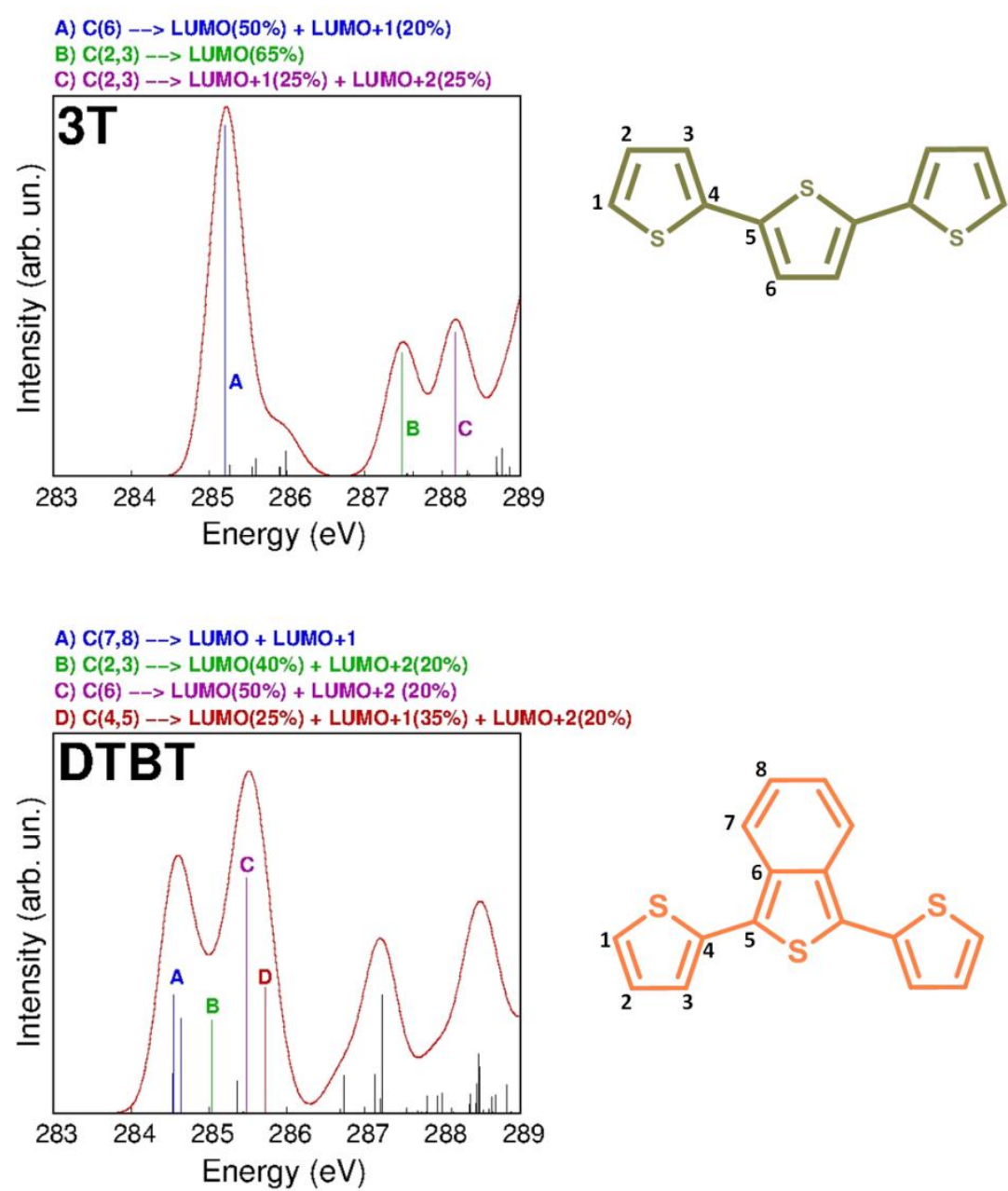

Figure S3. Calculated Carbon K-edge NEXAFS 3T (upper) and DTBT (lower) spectra.

NEXAFS spectra of the isolated 3T and DTBT molecules have been calculated in a time-dependent density functional theory (TDDFT) framework at the accurate B2PLYP³@def2-TZVPP level of theory. The def2-TZVPP basis set has been recontracted in order to keep into account relativistic effects in the Douglas-Kroll-Hess approach (see, for instance ref. ${ }^{4}$ ). The spectrum has been obtained as a convolution of Gaussian functions (fwmh $=0.5 \mathrm{eV}$ ) centered on the first 80 transitions, calculated by using a polarizability basis of 800 vectors connecting core levels with unoccupied states. A doubles correction to excitation energy has been calculated to further improve the accuracy of the results obtained with the double-hybrid B2PLYP approach. ${ }^{5}$ An analysis of the main transitions in terms of the ground-state B2PLYP vectors has been included to support the assignment of measured NEXAFS peaks (see the main body text). 
Experimental Carbon K-edge NEXAFS spectra of annealed DTBT after its deposition onto $\operatorname{Ag}(110)$ surface

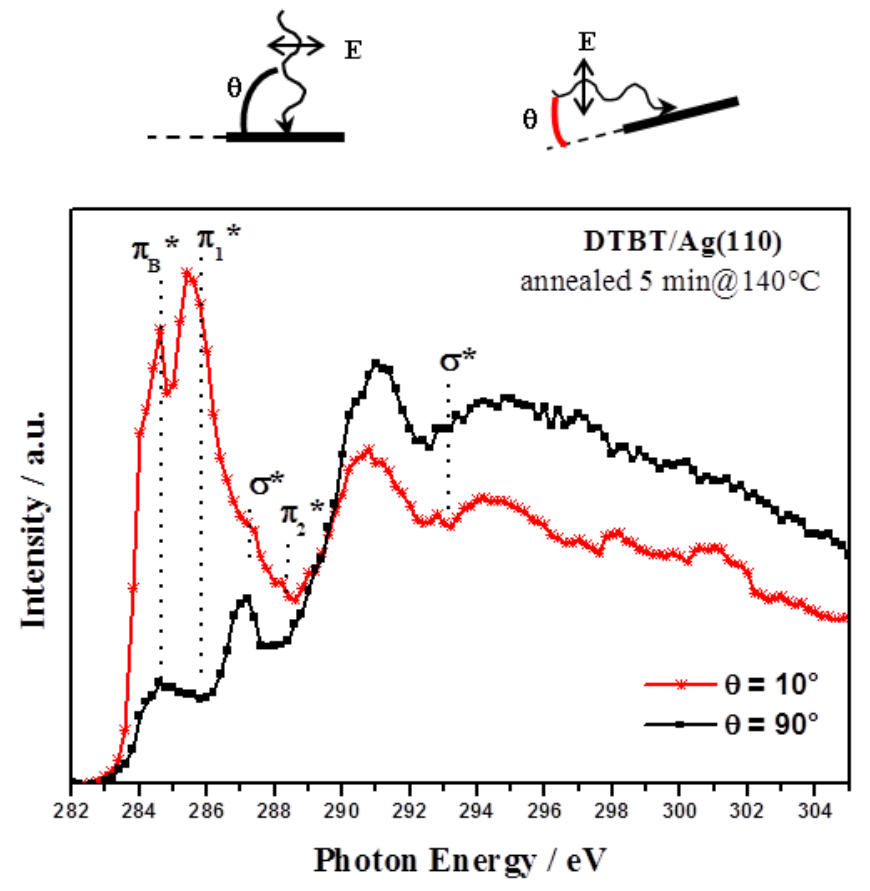

Figure S4. Carbon K-edge NEXAFS spectra of DTBT deposited by UHV onto Ag(110) surface and annealed for 5 min@ $140^{\circ} \mathrm{C}$ recorded at normal $\left(90^{\circ}\right)$ and grazing $\left(10^{\circ}\right)$ photon incidence angles (shown in the sketch outside the spectra). 


\section{Configurations of 3T and DTBT adsorbed on the Ag surface investigated by ab initio calculations}

Two preliminary series of calculations have been performed to find the stable conformers of the isolated 3T and DTBT molecules. Both PBE/PW and B3LYP/GTO calculations (see the theoretical method section reported in the main body text) suggest that the minimum energy configuration of the two molecules is characterized by a sort of "regio-regular" alternation of the thiophene units, with the central ring twisted by either $24^{\circ}$ or $40^{\circ}$ with respect to the external rings in the case of $3 \mathrm{~T}$ or DTBT, respectively. We have used such configuration in the further investigation of the interaction of the molecules with the $\mathrm{Ag}(110)$ surface. However, although the regio-regular-like configuration can be the most stable one for all the molecules and all the employed levels of theory, the small differences between relative energies reported in Table S-II, smaller than those calculated in the case of $\mathrm{P} 3 \mathrm{HT}^{6}$, do not exclude the formation of other conformers during the interaction of these molecules with the Ag surface.

Table S-II. Relative energies (in eV) of different conformers of the isolated $3 T$ and DTBT molecules, calculated at the PBE/PW and B3LYP/GTO levels of theory. The configurations are identified by labels indicating the alternation of the thiophene units (e.g., 121 indicates a regioregular-like alternation) and the planar $(p)$ or twisted $(t)$ reciprocal position of the thiophene rings.

$\begin{array}{lccccccc} & \text { 111p } & \text { 111t } & \text { 112p } & \mathbf{1 1 2 t} & \mathbf{1 2 1 p} & \mathbf{1 2 1 t} \\ \text { PBE/PW } & +0.06 & +0.05 & +0.03 & +0.02 & +0.01 & \mathbf{0 . 0 0} \\ \text { B3LYP/GTO } & +0.07 & +0.06 & +0.04 & +0.03 & +0.01 & \mathbf{0 . 0 0} \\ & & & \text { 3T } & & \\ & & & \text { DTBT } & & \\ \text { PBE/PW } & +0.02 & +0.01 & +0.01 & +0.01 & +0.06 & \mathbf{0 . 0 0} \\ & & & & & & \\ \text { B3LYP/GTO } & +0.02 & +0.01 & +0.02 & +0.01 & +0.04 & \mathbf{0 . 0 0}\end{array}$

The interaction of the two oligothiophenes with the Ag surface has been investigated by performing several calculations starting with the regio-regular-like molecules placed in different positions above the surface. Given the incommensurate ratio between the thiophene units and the surface lattice, we have alternatively placed the molecules, horizontally or vertically, above or between rows of surface of $\mathrm{Ag}$ atoms, as shown in Figure S4. More irregular placements, as well as 
herringbone configurations, have been also tried. Apart from such last herringbone configurations, characterized by higher relative energies, the tiny differences in the total energy values of the other configurations suggest that, at low coverages, the molecules are quite free to move over the $\mathrm{Ag}$ surface. A very similar situation was previously reported in the case of phthalocyanine molecules adsorbed on the $\operatorname{Ag}(100)$ surface, where such a statement was also supported by STM measurements. ${ }^{7}$ Despite this reported "flatness" of the potential energy surface of both 3T/Ag and DTBT/Ag systems, two general trends which characterize the molecule-surface interactions deserve to be highlighted: (i) no formation of chemical bonds between molecules and $\mathrm{Ag}$ atoms is found in any of the investigated configurations. This means that the molecules interact with the surface through strong dispersion forces, typical of such large, $\pi$-conjugated compounds, so that the electronic properties of the interface do not strictly depend on the adsorption site, (ii) the fused benzene ring of DTBT is never parallel to the Ag surface, thus confirming the results of NEXAFS measurements discussed in the main body text, while 3T arranges the reciprocal twisting of thiophene rings, never completely suppressed, in order to lay almost parallel to the Ag surface.
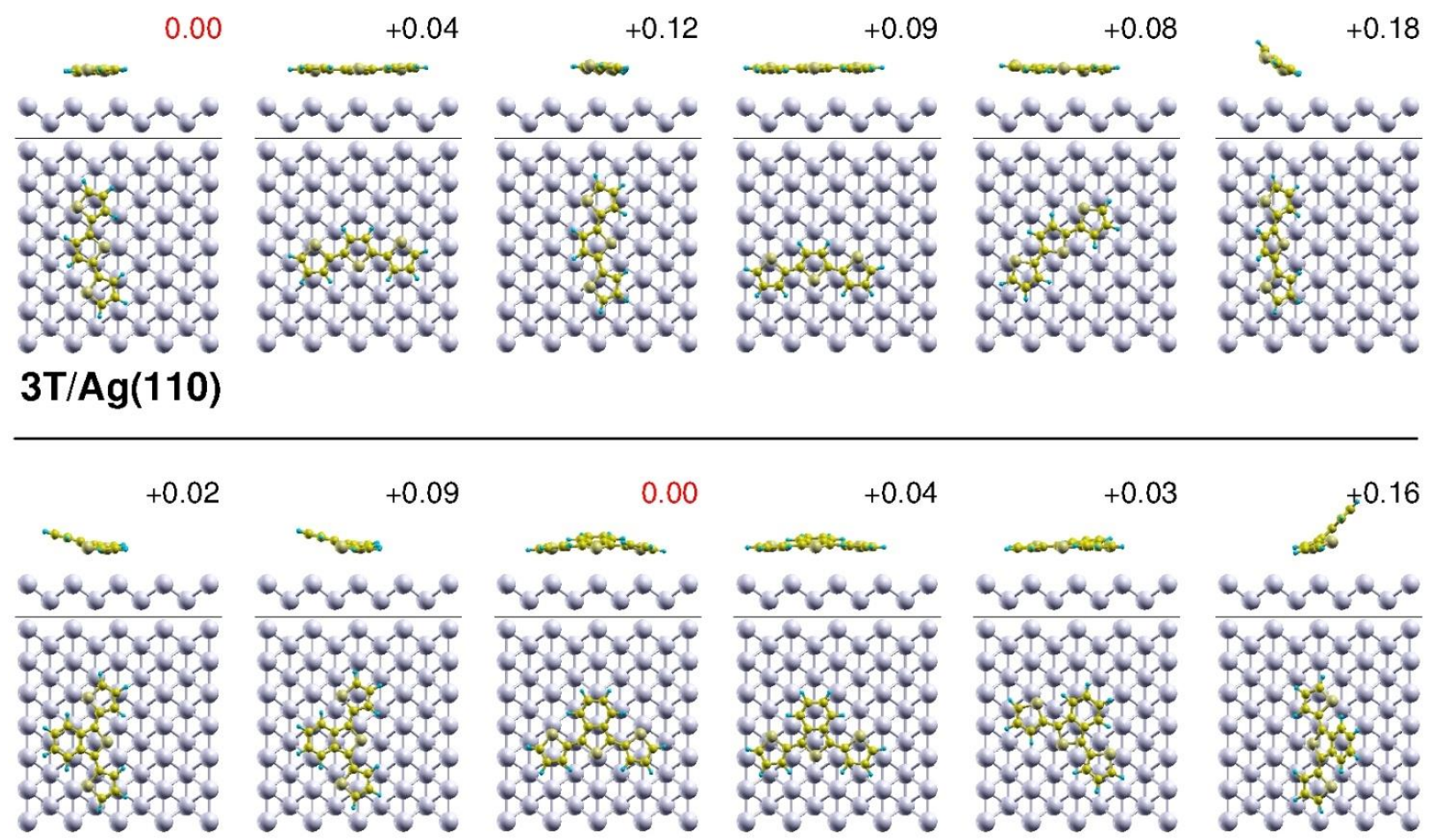

DTBT/Ag(110)

Figure S5. Side and top views of the investigated adsorption configurations of $3 T$ and DTBT onto the Ag(110) surface. Relative energies (in $\mathrm{eV}$ ) of the configurations are also indicated. 


\section{References}

(1) Bashouti M. Y.; Resch S.; Ristein J.; Mačković M.; Spiecker E.; Waldvogel S. R.; Christiansen S. H. Functionalization of Silver Nanowires Surface Using $\mathrm{Ag}-\mathrm{C}$ Bonds in a Sequential Reductive Method. ACS Appl. Mater. Interfaces 2015, 7 (39), 21657-21661.

(2) Huang Z.; Jiang H.; Liu P.; Sun J.; Guo D.; Shana J.; Gu N. Continuous Synthesis of SizeTunable Silver Nanoparticles by a Green Electrolysis Method and Multi-Electrode Design for High Yield. J. Mater. Chem. A 2015, 3, 1925-1929.

(3) Grimme, S. Semiempirical Hybrid Density Functional with Perturbative Second-Order Correlation. J. Chem. Phys., 2006,124, 034108.

(4) Neese, F.; Wolf, A.; Reiher, M.; Fleig, T.; Hess, B.A. Higher Order Douglas-Kroll Calculation of Electric Field Gradients. J. Chem. Phys. 2005, 122, 204107.

(5) Head-Gordon, M.; Rico, R. A.; Oumi, M.; Lee. T. J. A Doubles Correction to Electronic Excited States from Configuration Interaction in the Space of Single Substitutions. Chem. Phys. Letters 1994, 219, 21-29.

(6) Mattioli G.; Dkhil S. B.; Saba M. I.; Malloci G.; Melis C.; Alippi P.; Filippone F.; Giannozzi P.; Thakur A. K.; Gaceur M. et al. Interfacial Engineering of P3HT/ZnO Hybrid Solar Cells Using Phthalocyanines: A Joint Theoretical and Experimental Investigation. Adv. Energy Mater. 2014, 4, 1301694.

(7) Colonna S.; Mattioli G.; Alippi P.; Amore Bonapasta A.; Cricenti A.; Filippone F.; Gori P.; Paoletti A. M.; Pennesi G.; Ronci F. et al. Supramolecular and Chiral Effects at the Titanyl Phthalocyanine/Ag(100) Hybrid Interface. J. Phys. Chem. C 2014, 118, 5255. 